\title{
EFFECT OF CHLORIDE CONCENTRATION IN SOIL ON REINFORCEMENT CORROSION
}

\author{
By \\ M. Maslehuddin ${ }^{1 *}$, M. M. Al-Zahrani ${ }^{1}$, M. Ibrahim ${ }^{1}$, M. H. Al-Mehthel ${ }^{2}$, and S. H. Al- \\ $\mathrm{Idi}^{2}$
}

\begin{abstract}
This paper presents results of a study conducted to evaluate the effect of chloride concentration in soil on corrosion of reinforcing steel in concrete. Concrete specimens prepared with Type I, Type V and silica fume cements were exposed to soil with a chloride concentration of up to $3 \%$. The effect of chloride concentration in soil on corrosion of reinforcing steel was evaluated by measuring corrosion potentials and corrosion current density. After 18 months of exposure, the concrete specimens were broken and the extent of corrosion of the reinforcing steel was examined and the gravimetric weight loss due to corrosion was assessed. As expected, the degree of corrosion increased with the chloride concentration in the soil. The type of cement also influenced the reinforcement corrosion. For a particular chloride concentration, least reinforcement corrosion was noted in the silica fume cement concrete followed by Type I and Type V cement concrete. Based on the data developed in this study chloride threshold in soil for the three types of cements are suggested.
\end{abstract}

${ }^{1}$ Center for Engineering Research, Research Institute, King Fahd University of Petroleum and Minerals, Dhahran, 31261, Saudi Arabia

${ }^{2}$ Consulting Services Department, Saudi Aramco, Dhahran, Saudi Arabia.

*Corresponding author: Center for Engineering Research, Research Institute, King Fahd University of Petroleum and Minerals, Dhahran, Saudi Arabia.

Tel: +966-3-860 2853; Fax: +966-3-860 3996; E-mail: muddin@kfupm.edu.sa 


\section{INTRODUCTION}

Corrosion of reinforcing steel in concrete is predominantly caused by the chloride ions. The chloride ions may be contributed by the concrete mixture ingredients, such as aggregates, mix water, cement, and chemical or mineral admixtures. Alternatively, they may diffuse into the hardened concrete from the service environment. The chloride ions from the external environment diffuse through the concrete to the steel surface, leading to the depasivation of the protective $\gamma-\mathrm{Fe}_{2} \mathrm{O}_{3}$ layer and ultimately to the initiation of reinforcement corrosion. One such situation is the diffusion of chloride ions into the hardened concrete in substructures from the soil. While several standards [1, 2] provide information on the preventive measures for avoiding sulfate attack based on the sulfate concentration in the soil and ground water (for example, the type of cement, water-to-cement ratio, cement content, etc.), there are no guidelines on the chloride concentration in the soil and its influence on reinforcement corrosion.

While some information is available on the chloride threshold for corrosion of steel in concrete, data are lacking on the effect of chloride concentration in soil on reinforcement corrosion in substructures. This study was conducted to assess the effect of chloride concentration in the soil on reinforcement corrosion in plain and blended cement concretes. The findings of this study would be beneficial in selecting cement type appropriate for the chloride concentration in the soil. 


\section{METHODOLOGY OF RESEARCH}

\section{MATERIALS AND SPECIMEN PREPARATION}

The concrete mixtures were prepared with a cement content of $370 \mathrm{~kg} / \mathrm{m}^{3}$ and an effective water-to-cement ratio of 0.40 . Suitable dosage of a superplasticizer was added to the concrete mixture to obtain a slump of 50 to $75 \mathrm{~mm}$. The concrete mixtures were prepared with three types of cements, namely Type I, Type V and Type I plus silica fume. In the silica fume cement concrete mixture, $7 \%$ cement was replaced with silica fume.

Cylindrical concrete specimens, $75 \mathrm{~mm}$ in diameter and $150 \mathrm{~mm}$ high, with a single 12-mm diameter steel bar, that was placed in the center were prepared. To avoid crevice corrosion, the bottom of the bar and the concrete-air interface were coated with cement paste followed by an epoxy-based coating.

In order to evaluate the effect of chloride concentration in soil on reinforcement corrosion, reinforced concrete specimens were exposed to soil with a chloride concentration of $0.05,0.1,0.2,0.5,1.0,2.0$ and $3.0 \%$. The reinforced concrete specimens were placed in containers filled with contaminated soil such that only half their depth was exposed to the soil. The containers were stored under laboratory conditions and the soil was kept moist by spraying water from time to time.

Reinforcement corrosion in the concrete specimens exposed to soil with varying chloride concentration was monitored by measuring the corrosion potentials and corrosion current density. While measuring the corrosion potentials a saturated calomel reference electrode was placed near the concrete specimen. The corrosion 
current density (Icorr) was evaluated by the linear polarization method (LPRM) [3]. For measuring Icorr, a stainless steel rod placed close to the concrete specimen, as shown in Figure 1, was used as a counter electrode.

After 18 months of exposure to soil, the concrete specimens were broken to retrieve the reinforcing steel bars. The steel bars were then examined for the degree of reinforcement corrosion. The degree of reinforcement corrosion was identified on a qualitative scale varying from 0 to 5 . The corrosion rating and its description are detailed below:

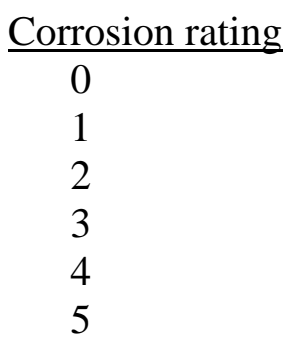

\begin{tabular}{l} 
Intensity of corrosion \\
\hline None \\
Minor \\
Minor to moderate \\
Moderate \\
Moderate to severe \\
Severe
\end{tabular}

After visual observation, the gravimetric weight loss of the steel bars, if any, was determined by cleaning them with the Clark's solution according to the procedure outlined in ASTM G1.

\section{RESULTS}

\section{Corrosion Potentials}

The corrosion potentials on steel bars in the concrete specimens exposed to soil with varying chloride concentration are plotted against period of exposure in Figures 2 through 8. Each point in these figures is the mean of measurements taken on three specimens.

According to the corrosion potentials in Figure 2 corrosion initiation was not noted in any of the concrete specimens exposed to soil with a chloride concentration of $0.05 \%$. 
However, the corrosion potential on steel in one of the Type $\mathrm{V}$ cement concrete specimens was less than $-270 \mathrm{mV}$ SCE after 562 days of exposure. The average corrosion potentials, as shown in Figure 3, indicate corrosion initiation in the Type V cement concrete specimens exposed to soil with a chloride concentration of $0.1 \%$ while corrosion did not initiate in Type I and silica fume cement concrete specimens, exposed to similar chloride concentration. However, corrosion initiation was noted in one of the Type I cement concrete specimens after about 437 days. In the concrete specimens exposed to soil with a chloride concentration of 2,000 ppm (Figure 4) corrosion initiation was noted after 369 days in Type V cement concrete specimens while corrosion did not initiate in the Type I and silica fume cement concrete specimens. The data in Figure 5 indicate corrosion initiation in the Type V and Type I cement concrete specimens only. Corrosion activation in these concrete specimens was noted after 195 and 455 days, respectively. The corrosion initiation in Type V, Type I and silica fume cement concrete specimens exposed to soil with a chloride concentration of 10,000 ppm was noted after 90, 210, and 510 days, respectively. In the Type V, Type I and silica fume cement concrete specimens exposed to soil with a chloride concentration of 20,000 ppm, corrosion initiation was noted after 55, 70, and 340 days, respectively. In the concrete specimens exposed to soil with a chloride concentration of 30,000 ppm these values were 50, 59, and 140 days, respectively.

The corrosion potential curves in Figures 2 through 8 were utilized to assess the time to initiation of reinforcement corrosion according to ASTM C 876 and these data are plotted against the chloride concentration in Figure 9. The data in Figure 9 indicate that the time to initiation of reinforcement corrosion is related to the chloride concentration in the soil and the type of cement. The time to initiation of reinforcement corrosion generally decreased with the chloride concentration in the 
soil. With regard to the type of cement, for a similar chloride concentration in the soil, corrosion initiated earlier in the Type V cement concrete specimens than in the Type I cement concrete specimens. Corrosion initiation was not noted in the silica fume cement concrete specimens exposed to soils with chloride concentration of $0.5 \%$ or less while in the soils with more than this chloride concentration the time to initiation of reinforcement corrosion in these cement concrete specimens was more than that in Type V and Type I cement concrete specimens. These data show the superior performance of silica fume cement concrete in resisting reinforcement corrosion compared to Type I and Type V cement concretes.

\section{Corrosion Current Density}

The Icorr on steel in the concrete specimens exposed to soil with varying chloride concentration is plotted in Figures 10 through 16.

The Icorr values increased with the period of exposure in all the concrete specimens. After 570 days of exposure, the Icorr generally increased with the chloride concentration in the soil. Further, the Icorr on steel in the Type V cement concrete specimens was more than that on steel in the Type I cement concrete specimens. Least Icorr was noted on steel in the silica fume cement concrete specimens. The Icorr was less than $0.3 \mu \mathrm{A} / \mathrm{cm}^{2}$ in the concrete specimens exposed to soil with a chloride concentration of $0.2 \%$ or less. The Icorr was more than $0.3 \mu \mathrm{A} / \mathrm{cm}^{2}$ in Type I and Type V cement concrete specimens exposed to soil with a chloride concentration of $0.5 \%$ or more while the Icorr on steel in the silica fume cement concrete specimens was more than the threshold value $\left(0.3 \mu \mathrm{A} / \mathrm{cm}^{2}\right)$ when exposed to soil with a chloride concentration of $1 \%$ or more. 
Figure 17 shows the effect of chloride concentration in the soil on Icorr at the end of the exposure. The Icorr increased with increasing chloride concentration in the soil, and as stated earlier the Icorr on steel in the silica fume cement concrete was less than that on steel in the plain cement concrete specimens. Among plain cements, the Icorr on steel in Type I cement concrete specimens was less than that on steel in Type V cement concrete specimens.

\section{Visual Examination and Gravimetric Weight Loss}

The concrete specimens exposed to soil with varying chloride concentration were broken to retrieve the steel bars. The steel bars were examined visually for the degree of corrosion and then the gravimetric weight loss was determined. Table 1 summarizes the corrosion ratings.

Corrosion of reinforcing steel was not noted in any of the concrete specimens exposed to soil with a chloride concentration of $0.05 \%$. Minor reinforcement corrosion was noted in the Type $\mathrm{V}$ cement concrete specimens exposed to soil with a chloride concentration of $0.1 \%$ while corrosion was not noted in the Type I and silica fume cement concrete specimens similarly exposed. Minor corrosion of the reinforcing steel bars was noted in Type V cement concrete specimens exposed to soil with a chloride concentration of $0.2 \%$ while corrosion was not noted on the steel bars in Type I and silica fume cement concrete specimens. Minor to moderate corrosion (rating of 2) was noted on the steel bars in Type I and Type V cement concrete specimens exposed to soil with a chloride concentration of $0.5 \%$ while corrosion was not noted on the steel bars in the silica fume cement concrete specimens. Moderate corrosion (rating of 3) was noted on the steel bars in the Type V cement concrete specimens exposed to soil with a chloride concentration of $1 \%$ while minor to 
moderate (rating of 2) and minor (rating of 1) corrosion was noted on the steel bars in the Type I cement concrete specimens. Moderate corrosion was noted on the steel bars in the Type $\mathrm{V}$ cement concrete specimens exposed to soil with chloride concentrations of $2 \%$ and $3 \%$, respectively; while minor to moderate and minor corrosion was noted in the Type I and silica fume cement concrete specimens, respectively.

Gravimetric weight loss is plotted against chloride concentration in Figure 18. Gravimetric weight loss was noted in Type V cement concrete specimens exposed to soil with a chloride concentration of $0.1 \%$ or more, while in Type I cement concrete specimens this phenomenon was noted in the concrete specimens exposed to soil with a chloride concentration of $0.5 \%$ or more. The gravimetric weight loss was noted in silica fume cement concrete specimens exposed to soil with a chloride concentration of $1 \%$ or more. In all the concrete specimens the gravimetric weight loss increased with the chloride concentration in the soil. Further, the gravimetric weight loss in the Type V cement concrete specimens was more than that in Type I and silica fume cement concrete specimens. The gravimetric weight loss in the silica fume cement concrete specimens was less than that in Type I cement concrete specimens.

\section{DISCUSSION}

The time-corrosion potential curves, shown in Figures 2 through 8, were utilized to assess the time to initiation of reinforcement corrosion, according to ASTM C 876 criterion and plotted in Figure 9. As is evident from the data in Figure 9, initiation of reinforcement corrosion was noted in the Type V cement concrete specimens exposed to soil with a chloride concentration of $0.1 \%$ or more while it was noted in the Type I cement concrete specimens exposed to soil with a chloride concentration of $0.5 \%$ or 
more. Corrosion initiation was noted in the silica fume cement concrete specimens exposed to soil with a chloride concentration of $1 \%$ or more. Further, the time to initiation of reinforcement corrosion decreased with the chloride concentration in the soil. Reinforcement corrosion started earlier in Type V cement concrete specimens compared to Type I and silica fume cement concrete specimens. The time to initiation of reinforcement corrosion in the silica fume cement concrete specimens was less than that in the Type I cement concrete specimens.

The Icorr on steel in the concrete specimens exposed to soils with a chloride concentration of less than $0.2 \%$ was low while it was more than $0.3 \mu \mathrm{A} / \mathrm{cm}^{2}$ in the Type I and Type V cement concrete specimens exposed to soils with a chloride concentration of $0.5 \%$ or more. The Icorr was more than $0.3 \mu \mathrm{A} / \mathrm{cm}^{2}$ in the silica fume cement concrete specimens exposed to soil with a chloride concentration of $1 \%$ or more. The Icorr generally increased with increasing chloride concentration in the soil.

Visual observation of the reinforcing steel bars retrieved from the concrete specimens exposed to soil with varying chloride concentration also revealed no corrosion to minor corrosion in the Type I and Type V cement concrete specimens exposed to soil with a chloride concentration of up to $0.2 \%$. The intensity of corrosion in the plain cement concrete sppecimens increased when they were exposed to soil with a chloride concentration of $0.5 \%$ or more. The intensity of corrosion was minor in the silica fume cement concrete specimens exposed to soil with a chloride concentration of $1 \%$, $2 \%$ and $3 \%$.

The gravimetric weight loss data also indicated the superior performance of silica fume cement concrete specimens compared to the plain cement concrete specimens. 
In the plain cement concrete specimens the gravimetric weight loss of steel bars in the Type I cement concrete specimens was less than that of steel bars in the Type V cement concrete specimens. These data corroborate the findings of the visual survey, and electrochemical measurements.

The data on reinforcement corrosion pertaining to the concrete specimens exposed to soil with varying chloride concentrations indicated two trends: (i) reinforcement corrosion was influenced by the chloride concentration in the soil, and (ii) the type of cement also significantly affected reinforcement corrosion. Discussing the first finding first, the data developed in this study indicate that adequate corrosion protective measures need to be taken when concrete structures are to be placed in soils contaminated with chlorides. In the case of Type V cement concrete, the chloride threshold level is as low as $0.1 \%$ while it is $0.5 \%$ and $1.0 \%$ for the Type I and silica fume cement concrete, respectively. The protective measures may include: (i) appropriate mix design, (ii) coating of concrete (iii) protecting the reinforcing steel through the use of fusion bonded epoxy or other coatings, and (iv) use of corrosionresistant steel.

The other aspect of the findings of this research is the effect of the cement type on reinforcement corrosion. The data on corrosion potentials, corrosion current density, visual ratings and gravimetric weight loss all indicate the superior performance of silica fume cement concrete over Type I and Type V cement concretes. Among plain cements, the performance of Type I cement was better than that of Type V cement.

The superior performance of Type I cement compared to Type V cement, in decreasing reinforcement corrosion may be attributed to its increased chloride binding capacity. The superior performance of silica fume cement concrete compared to plain 
cement concretes may be attributed to its dense structure that reduces the diffusion of the chloride ions to the steel surface. The dense structure of silica fume cement also increases the electrical resistivity of concrete resulting in a decrease in the rate of reinforcement corrosion. Therefore, it is an intelligent option to utilize silica fume cement concrete in the structures exposed to soils with a chloride concentration of $1 \%$ and more. However, there may be concern as to the use of silica fume cement concrete in sulfate-bearing soils, particularly with high concentrations of magnesium sulfate. Accelerated deterioration of silica cement concrete exposed to high concentrations of magnesium sulfate has been reported in the literature [4-6]. Therefore, structures cast with silica fume cement concrete and located in soil or groundwater contaminated with high concentrations of magnesium sulfate should be protected by the application of a protective coating.

\section{CONCLUSIONS}

1. Corrosion initiation was not indicated in the Type $\mathrm{V}$ cement concrete specimens exposed to soil with a chloride concentration of up to $0.05 \%$ while passivity was maintained in the Type I and silica fume cement concrete specimens exposed to soils with chloride concentration of up to $0.2 \%$ and $0.5 \%$, respectively. The time to initiation of reinforcement corrosion decreased with increasing chloride concentration in the soil.

2. The corrosion current density also increased with the chloride concentration in the soil. The corrosion current density on steel was more than $0.3 \mu \mathrm{A} / \mathrm{cm}^{2}$ in the Type I and Type V cement concrete specimens exposed to soil with a chloride concentration of more than $0.5 \%$. The corrosion current density on 
steel in the silica fume cement concrete specimens was more than $0.3 \mu \mathrm{A} / \mathrm{cm}^{2}$ when they were exposed to soil with chloride concentration of $1 \%$ or more.

3. On visual examination, corrosion was not noted in any of the concrete specimens exposed to soil with a chloride concentration of $0.05 \%$. Reinforcement corrosion was observed in the Type $\mathrm{V}$ cement concrete specimens exposed to soil with a chloride concentration of $0.1 \%$ and more while it was noted in the Type I cement and silica fume cement concretes for chloride concentrations of $0.5 \%$ and $1 \%$, respectively.

4. Gravimetric weight loss was noted in the Type V cement concrete specimens exposed to soil with a chloride concentration of $0.1 \%$ or more while in the Type I cement concrete specimens it was noted for a chloride concentration of $0.5 \%$ or more. Gravimetric weight loss was noted in the silica fume cement concrete specimens exposed to a chloride concentration of $1 \%$ or more.

5. The type of cement had a significant effect on the corrosion-resistance of concrete. Highest corrosion activity on steel was noted in the concrete specimens prepared with Type V cement, while it was the least on steel in the cement concrete specimens prepared with Type I cement blended with 7\% silica fume.

\section{RECOMMENDATIONS}

Since the results of this study have shown that the type of cement significantly influences the corrosion-resistance of concrete, the type of cement should be based on the chloride concentration in the soil. The recommended cement for the chloride concentration in the soil is noted below: 
Chloride concentration in soil

Less than $0.1 \%$

$0.1 \%$ to $0.5 \%$

More than $0.5 \%$

\section{Recommended cement}

Type V

Type I

Type I + 7\% silica fume

\section{REFERENCES}

1. $\quad$ British Standards Institution (1985). The Structural Use of Concrete BS 8110: Part 1.

2. $\quad$ American Concrete Institute, ACI 318 (1996). Building Code Requirements for Reinforced Concrete, American Concrete Institute, Detroit.

3. Stern, M. and A. L. Geary (1957). A theoretical analysis of the slope of the polarization curves, Journal of Electrochemical Society, v. 104, p. 56.

4. Rasheeduzzafar, Al-Amoudi O. S. B., Abduljawad S. N. and Maslehuddin, M. Magnesium-sodium sulfate attack in plain and blended cements. Journal of Materials in Civil Engineering May, 1994; 6(2): 201-222.

5. Al-Amoudi O. S. B., Maslehuddin, M. and Saadi, M. M. Effect of magnesium sulfate sodium on the durability performance of plain and blended cements. ACI Materials Journal Jan-Feb. 1955; 92(1): 15-24.

6. Cohen M. D. and Bentur, A. Durability of Portland cement-silica fume pastes in magnesium sulfate and sodium sulfate solutions. ACI Materials Journal 1988; 85(3): 148-157. 
Table 1. Corrosion ratings for steel bars in the concrete specimens exposed to soil with varying chloride concentration.

\begin{tabular}{|c|c|c|c|}
\hline \multirow{2}{*}{$\begin{array}{l}\text { Chloride } \\
\text { concentration in } \\
\text { the soil, \% }\end{array}$} & \multicolumn{3}{|c|}{ Corrosion rating* } \\
\hline & $\begin{array}{l}\text { Type I } \\
\text { cement }\end{array}$ & $\begin{array}{l}\text { Type V } \\
\text { cement }\end{array}$ & $\begin{array}{c}\text { Silica fume } \\
\text { cement }\end{array}$ \\
\hline 0.05 & 0 & 0 & 0 \\
\hline 0.1 & 0 & 1 & 0 \\
\hline 0.2 & 0 & 1 & 0 \\
\hline 0.5 & 2 & 2 & 0 \\
\hline 1.0 & 2 & 3 & 1 \\
\hline 2.0 & 2 & 3 & 1 \\
\hline 3.0 & 2 & 3 & 1 \\
\hline
\end{tabular}

* Corrosion rating: 0: No corrosion; 1: Minor corrosion; 2: Minor to moderate corrosion;

3: Moderate corrosion; 4: Moderate to severe corrosion; 5: Severe corrosion 


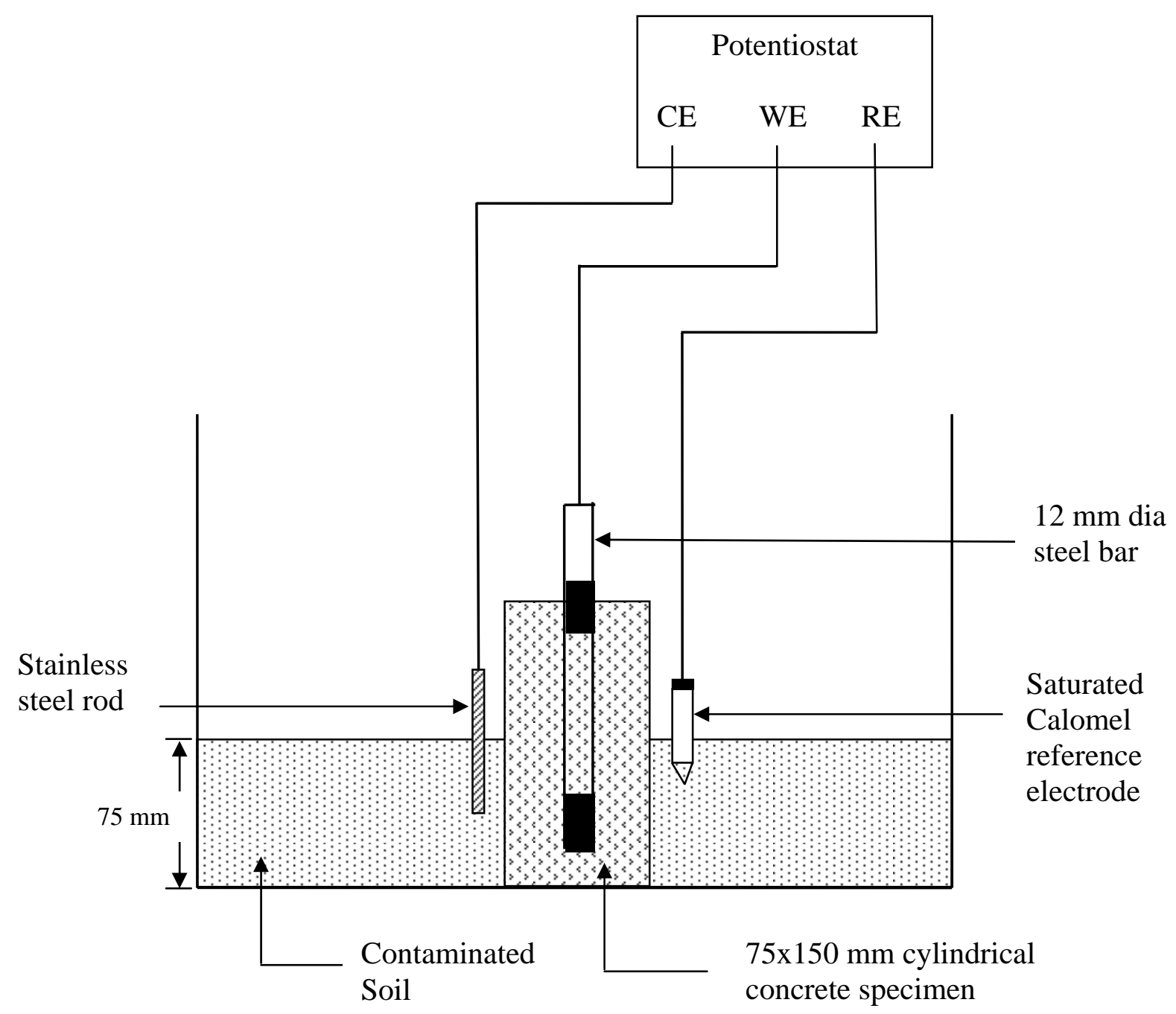

Figure 1 Schematic representation of the experimental set-up utilized to measure corrosion current density on steel in the concrete specimens. 


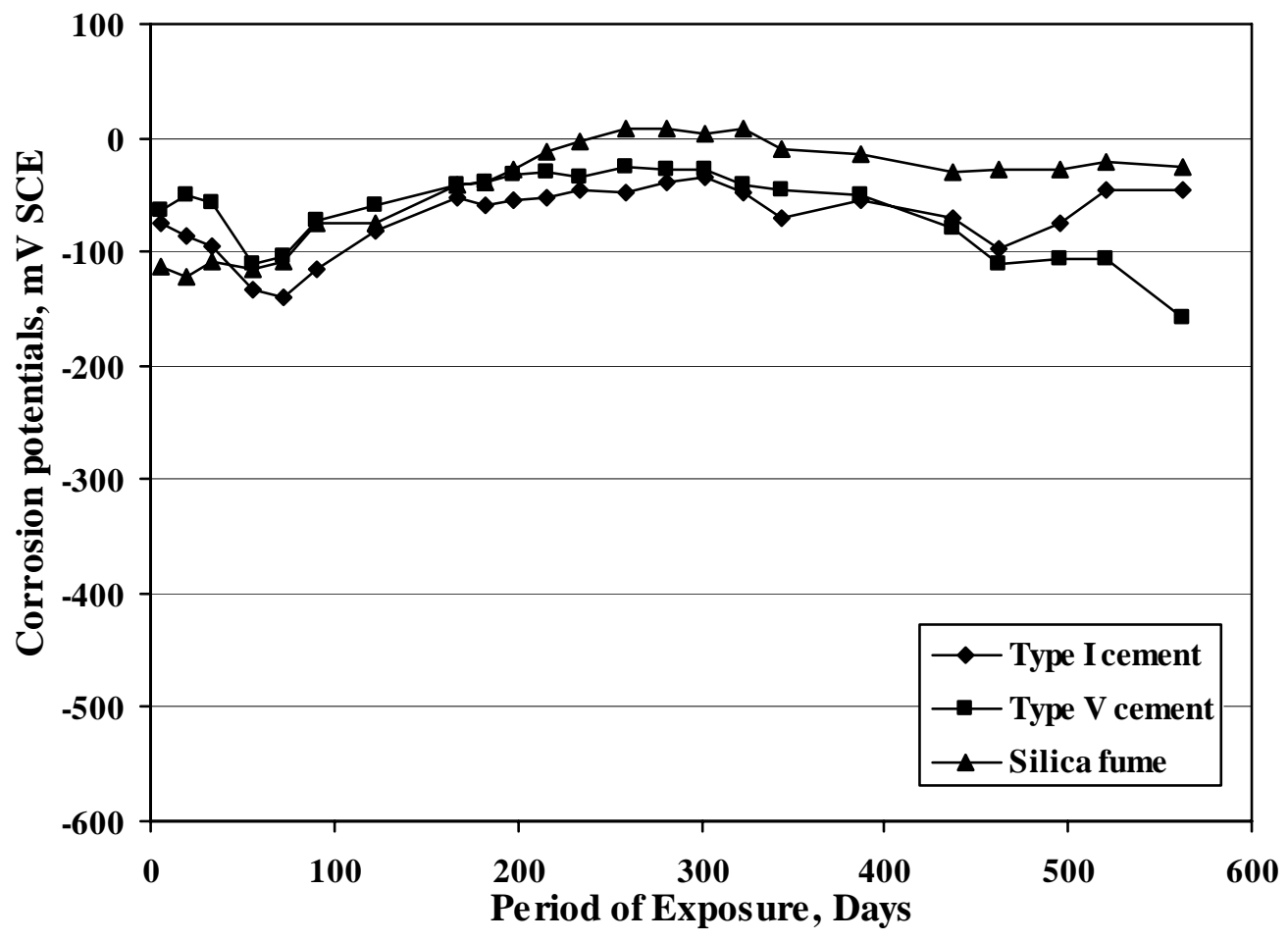

Figure 2 Corrosion potentials on steel in the concrete specimens exposed to soil with a chloride concentration of $0.05 \%$.

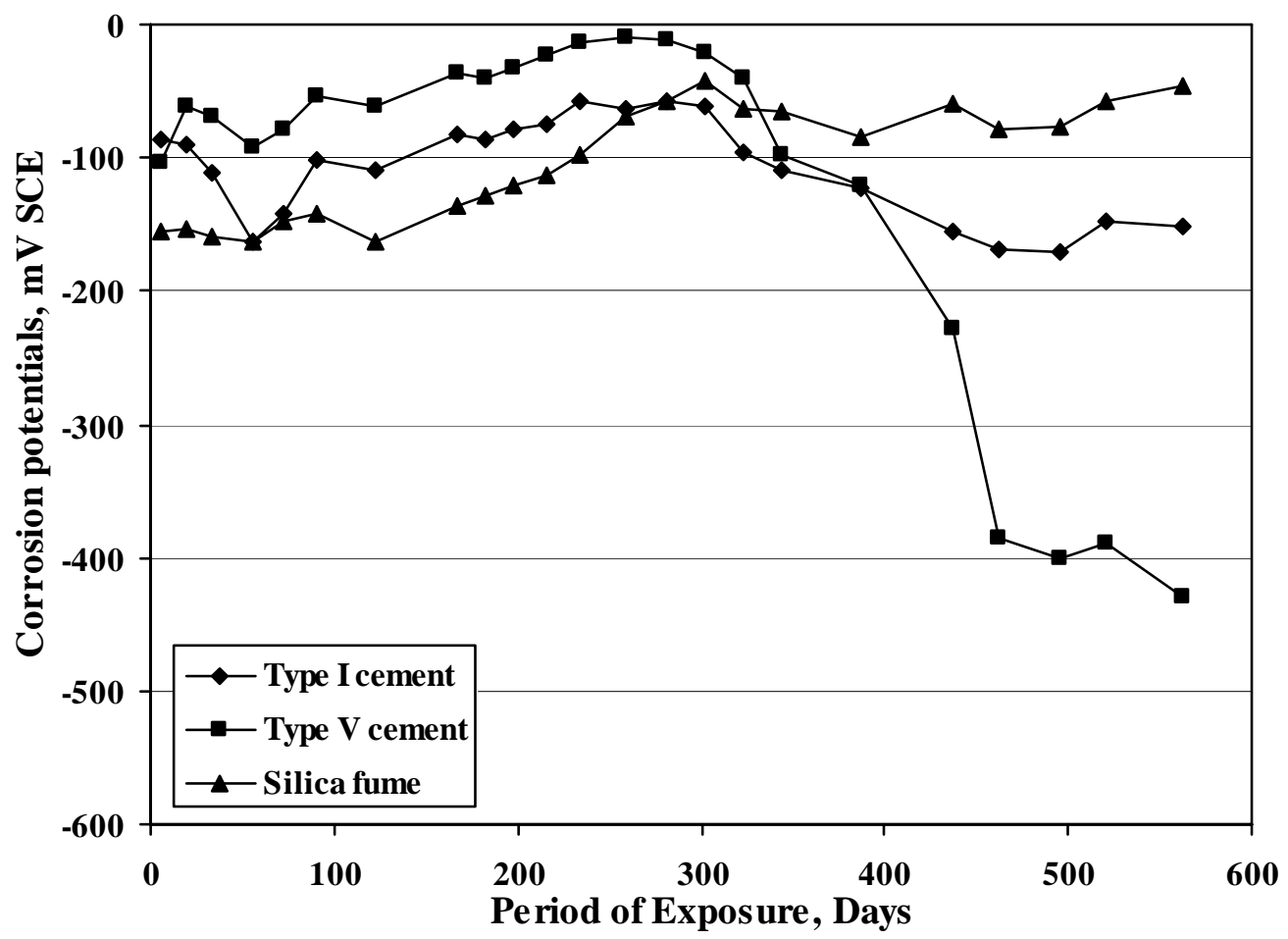

Figure 3 Corrosion potentials on steel in the concrete specimens exposed to soil with a chloride concentration of $0.1 \%$. 


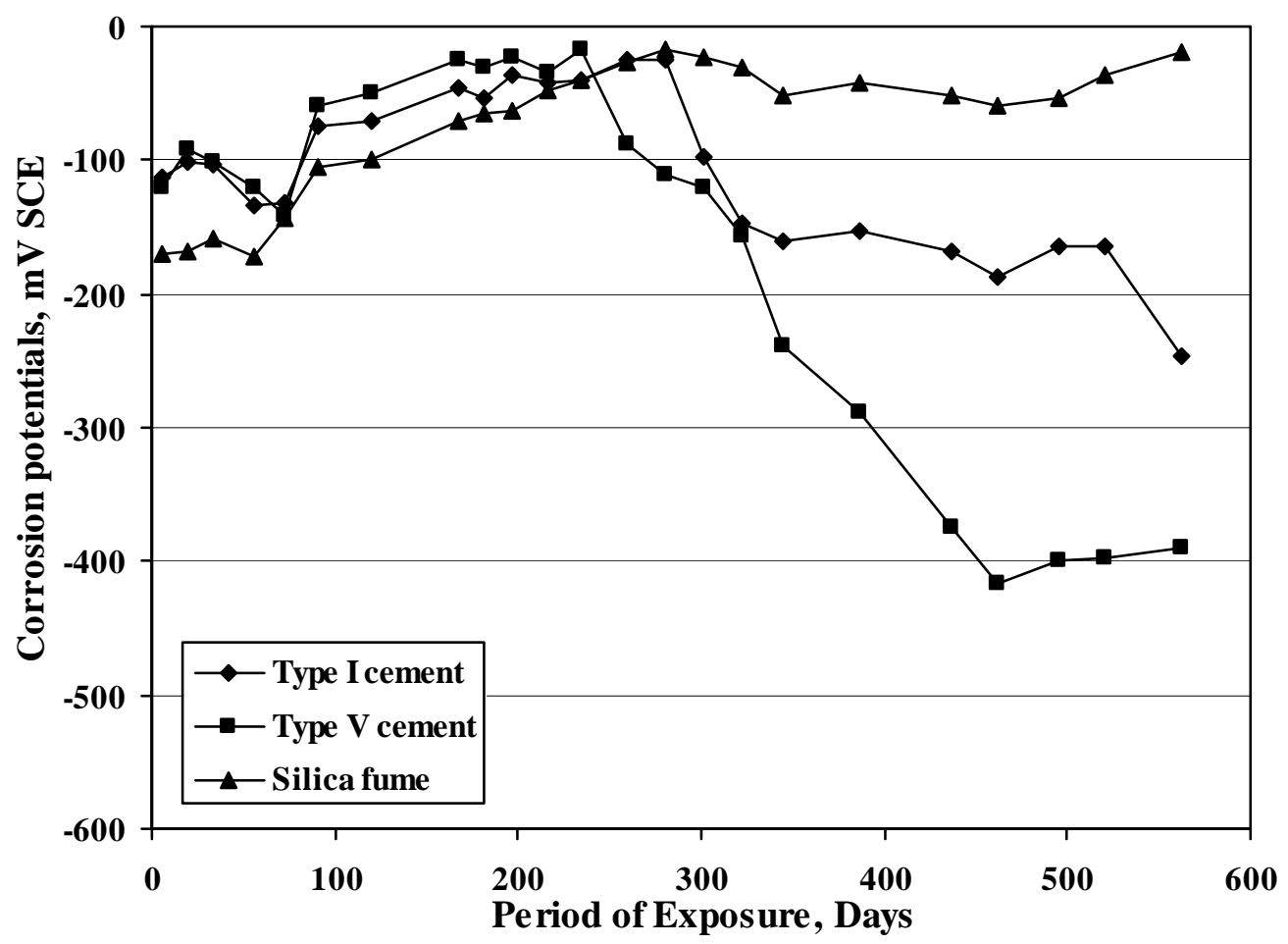

Figure 4 Corrosion potentials on steel in the concrete specimens exposed to soil with a chloride concentration of $0.2 \%$.

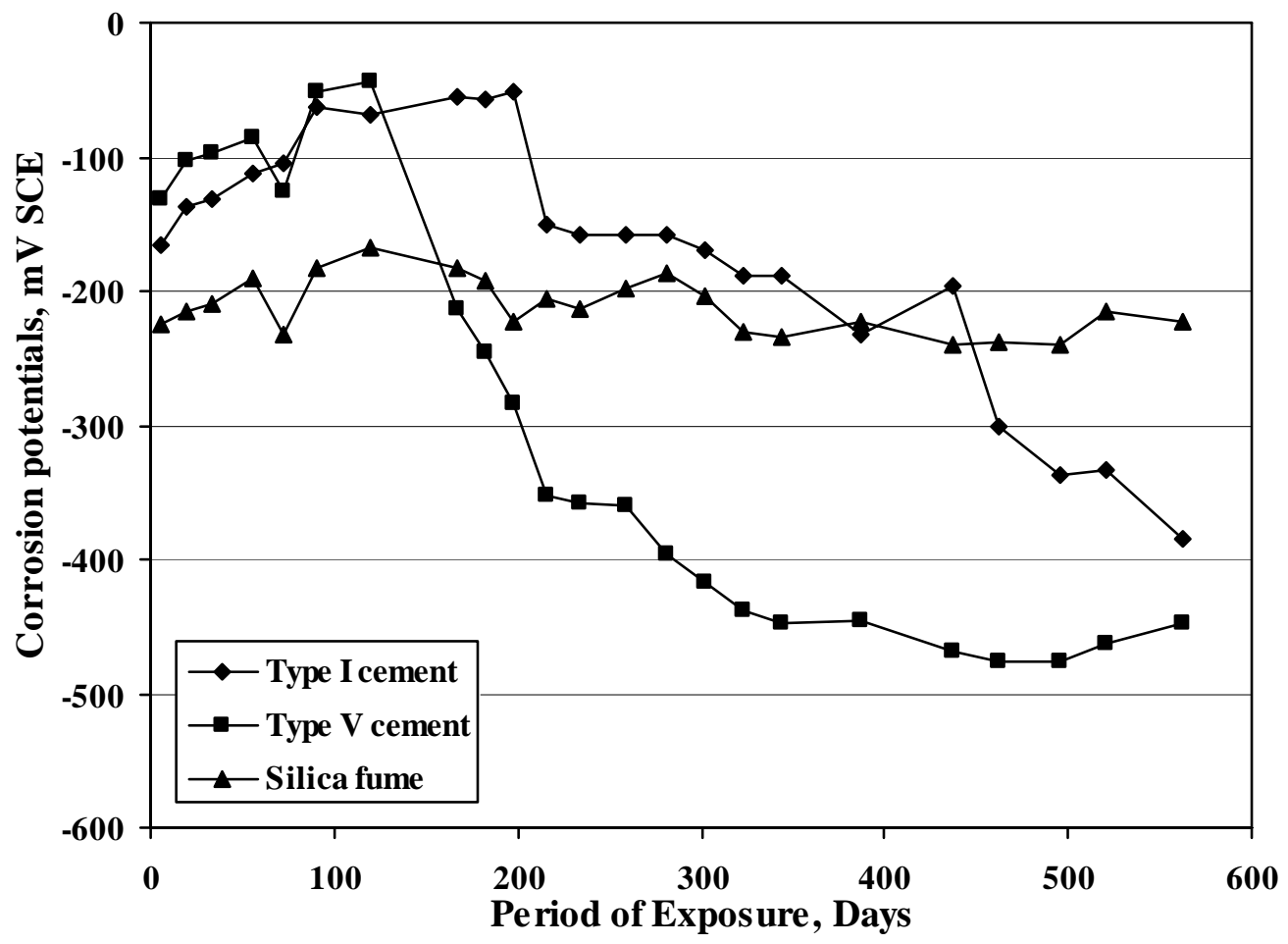

Figure 5 Corrosion potentials on steel in the concrete specimens exposed to soil with a chloride concentration of $0.5 \%$. 


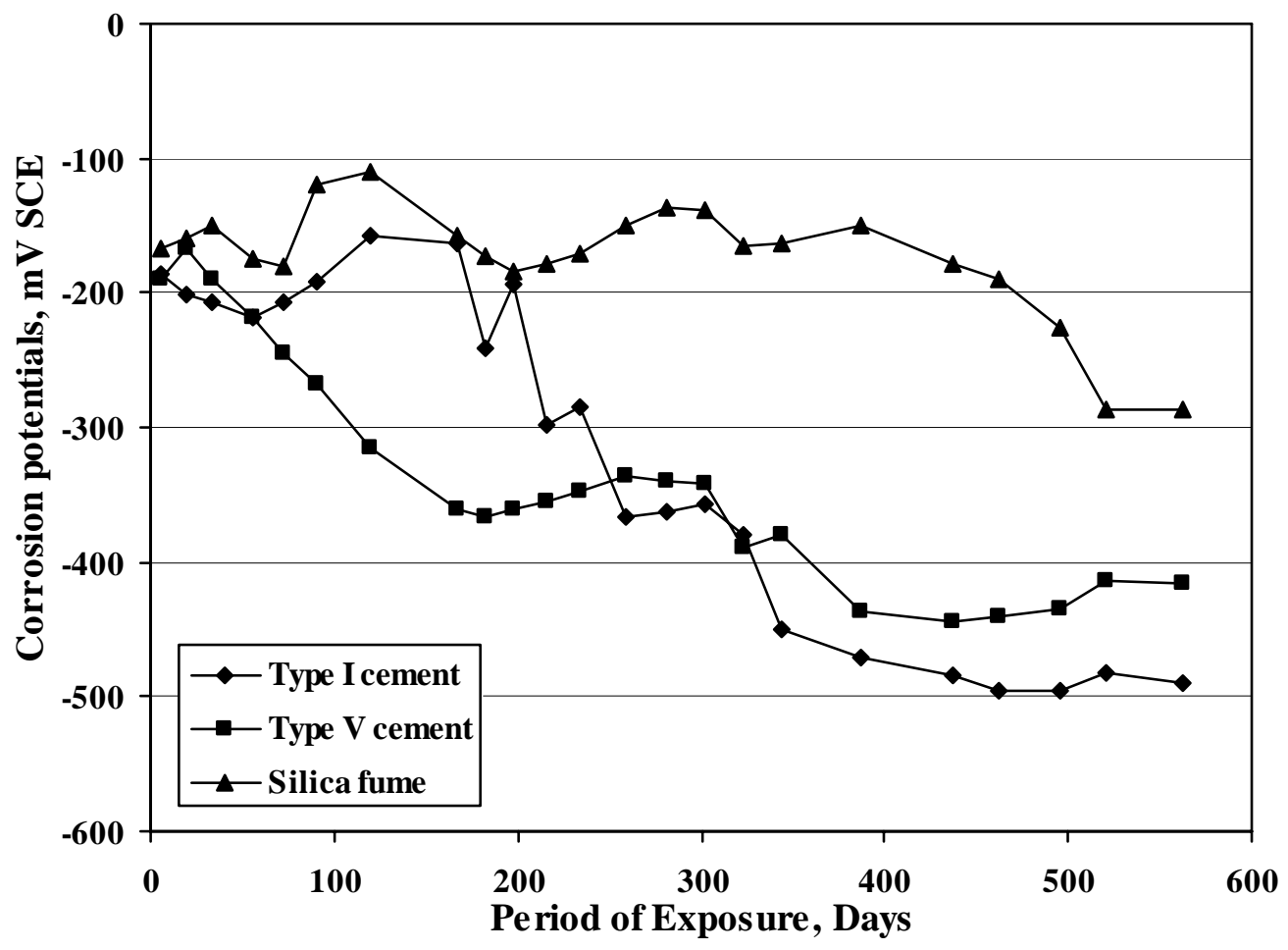

Figure 6 Corrosion potentials on steel in the concrete specimens exposed to soil with a chloride concentration of $1 \%$.

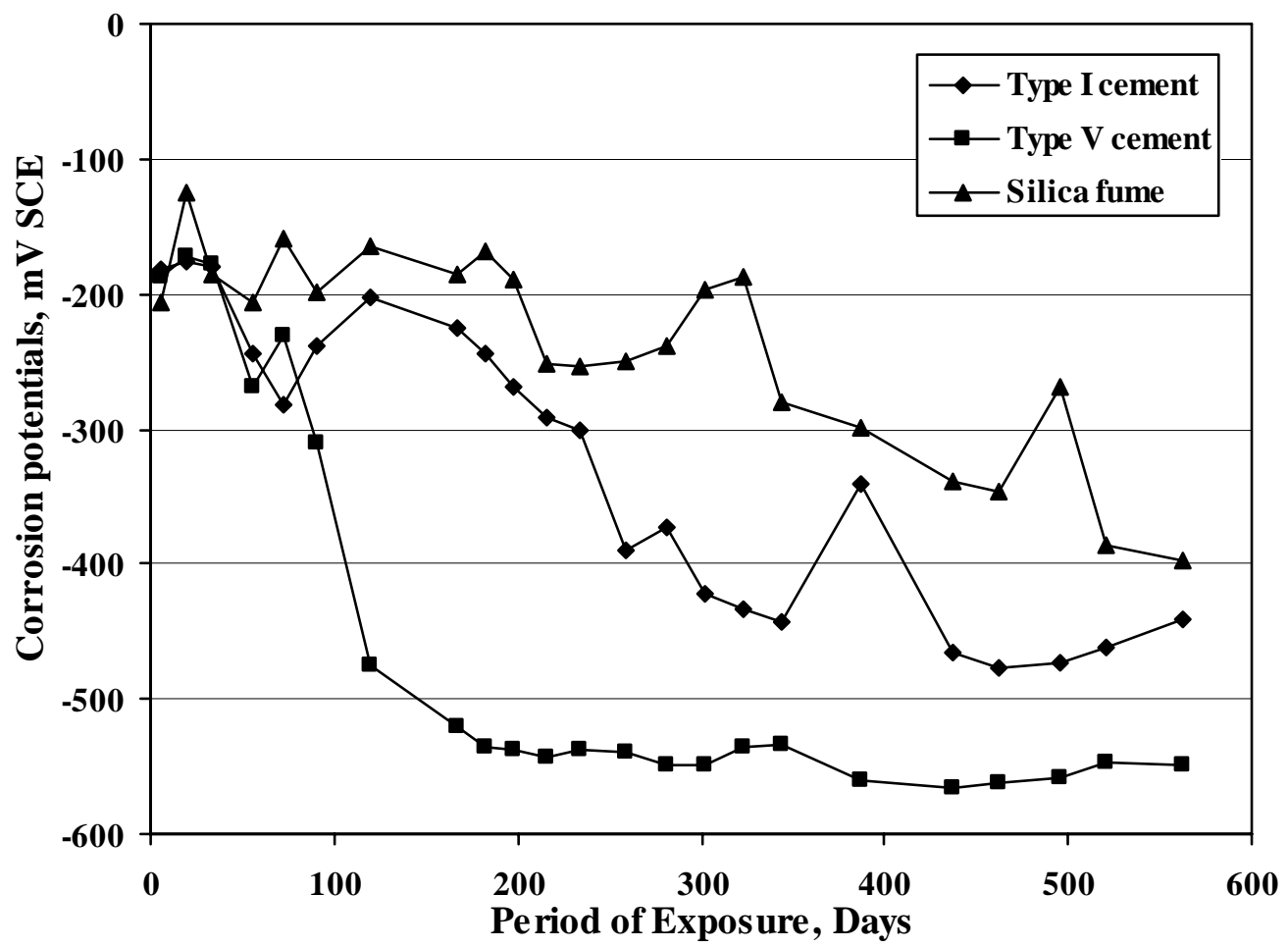

Figure 7 Corrosion potentials on steel in the concrete specimens exposed to soil with a chloride concentration of $2 \%$. 


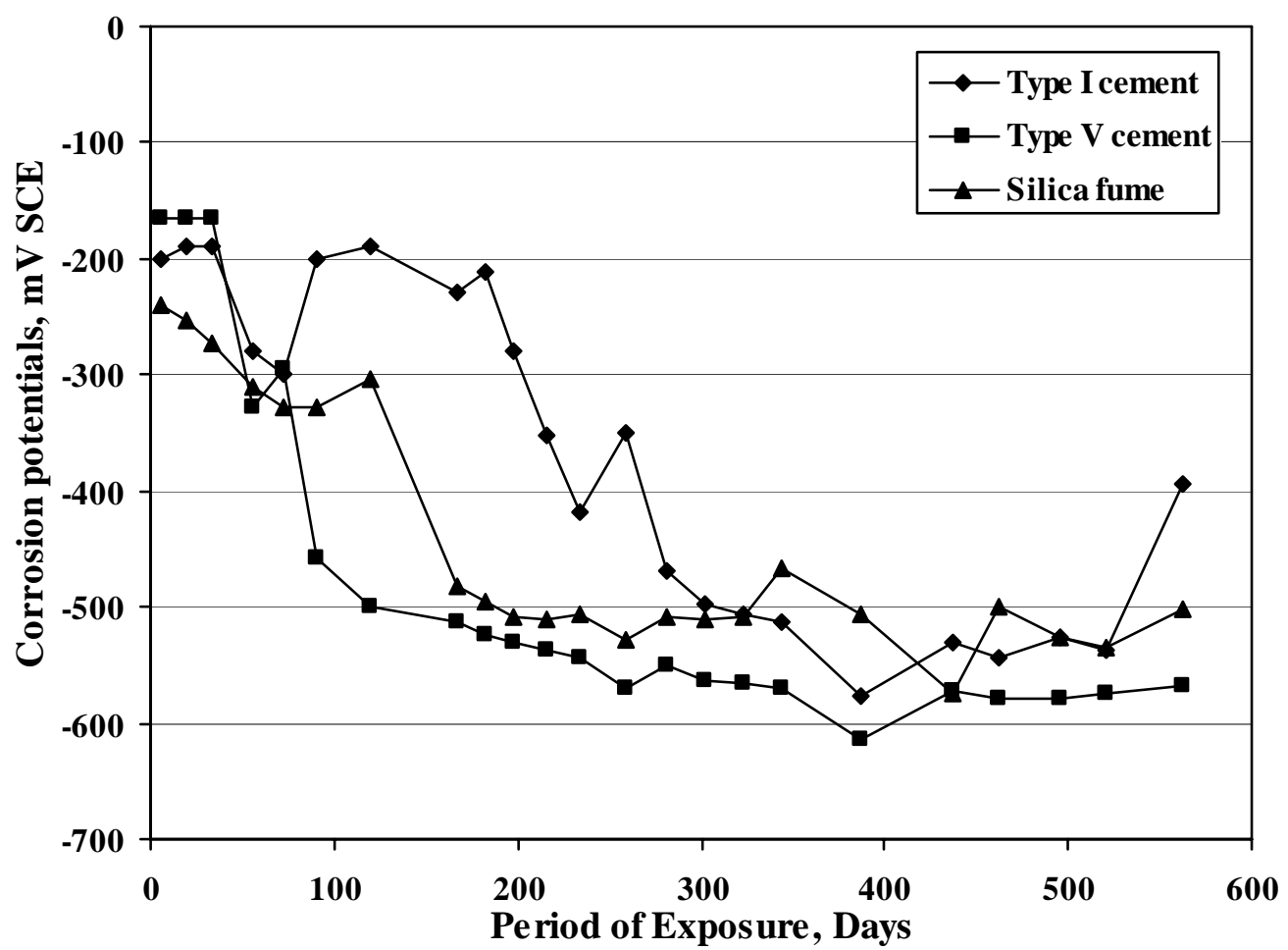

Figure 8 Corrosion potentials on steel in the concrete specimens exposed to soil with a chloride concentration of $3 \%$.

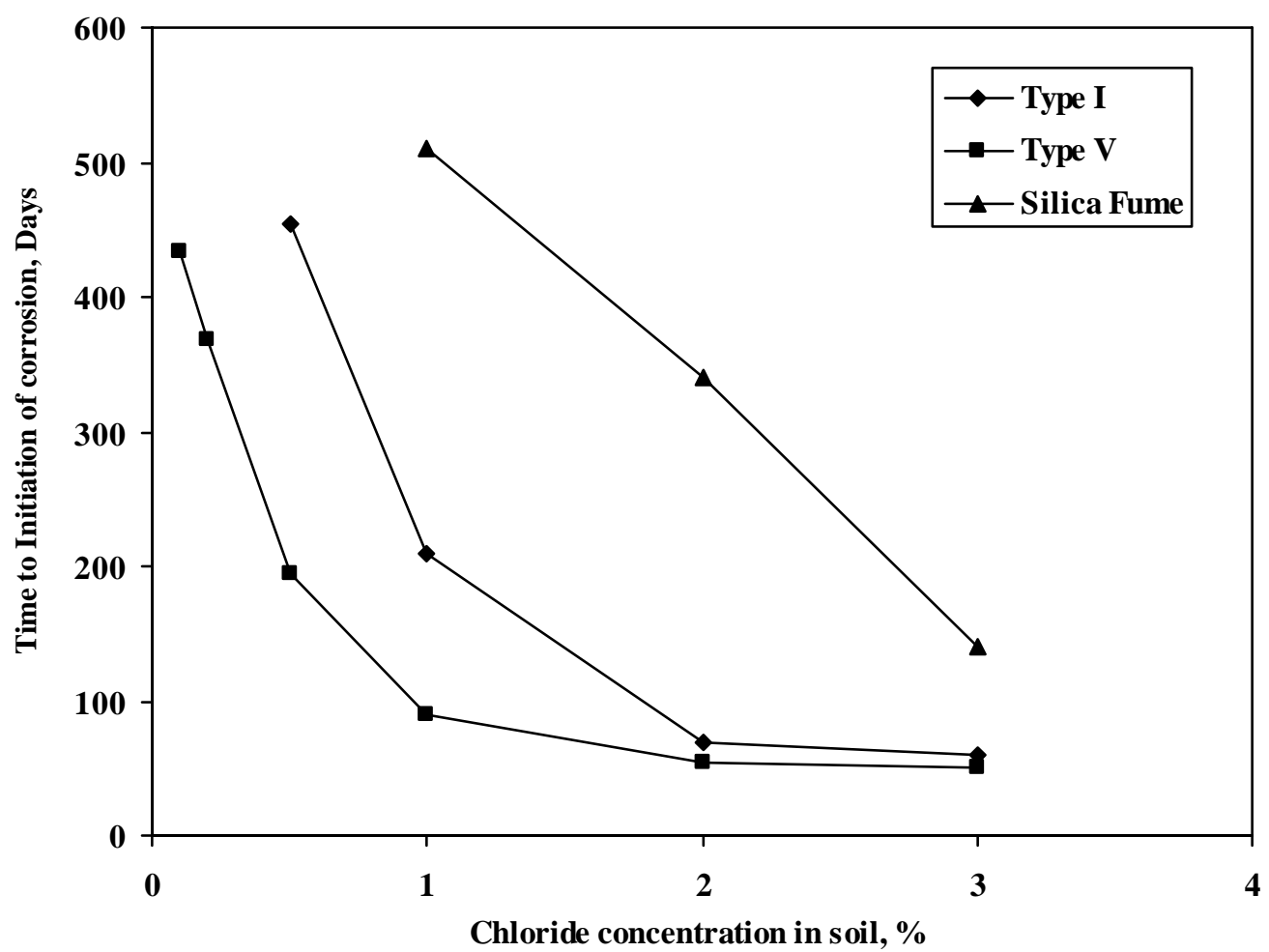

Figure 9 Time to initiation of reinforcement corrosion in the concrete specimens exposed to soil with varying chloride concentration. 


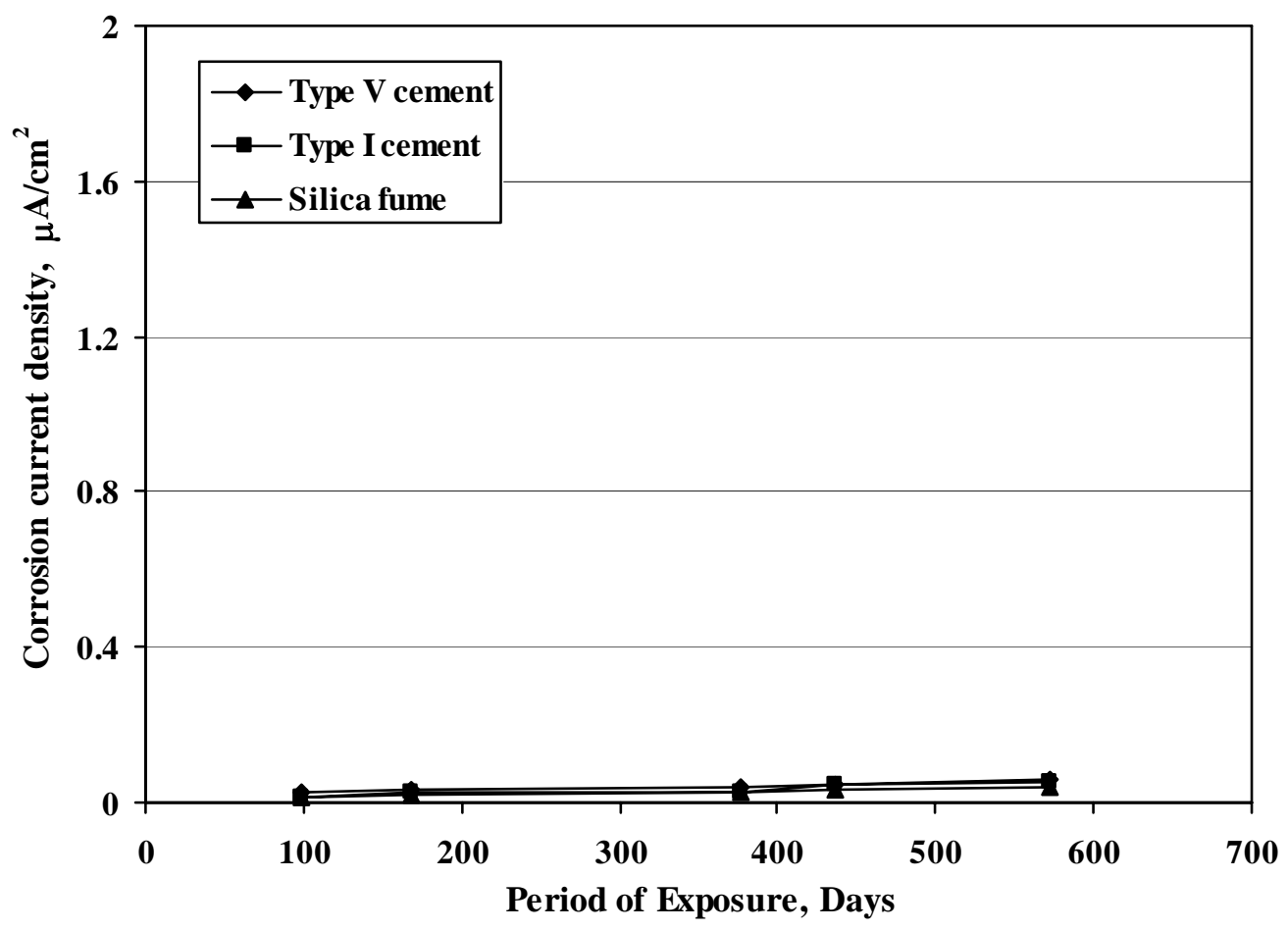

Figure 10 Corrosion current density on steel in the concrete specimens exposed to soil with a chloride concentration of $0.05 \%$.

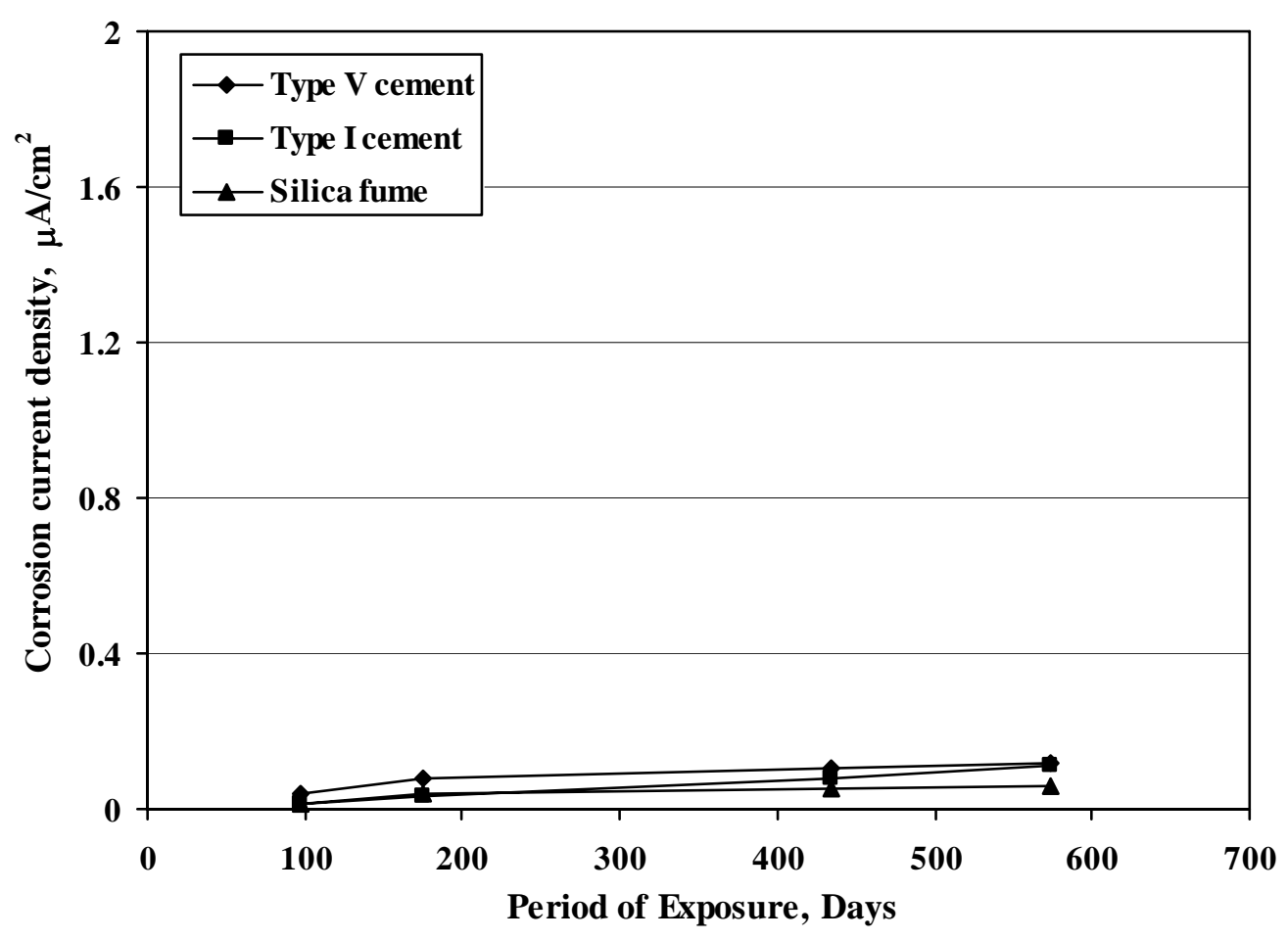

Figure 11 Corrosion current density on steel in the concrete specimens exposed to soil with a chloride concentration of $0.1 \%$. 


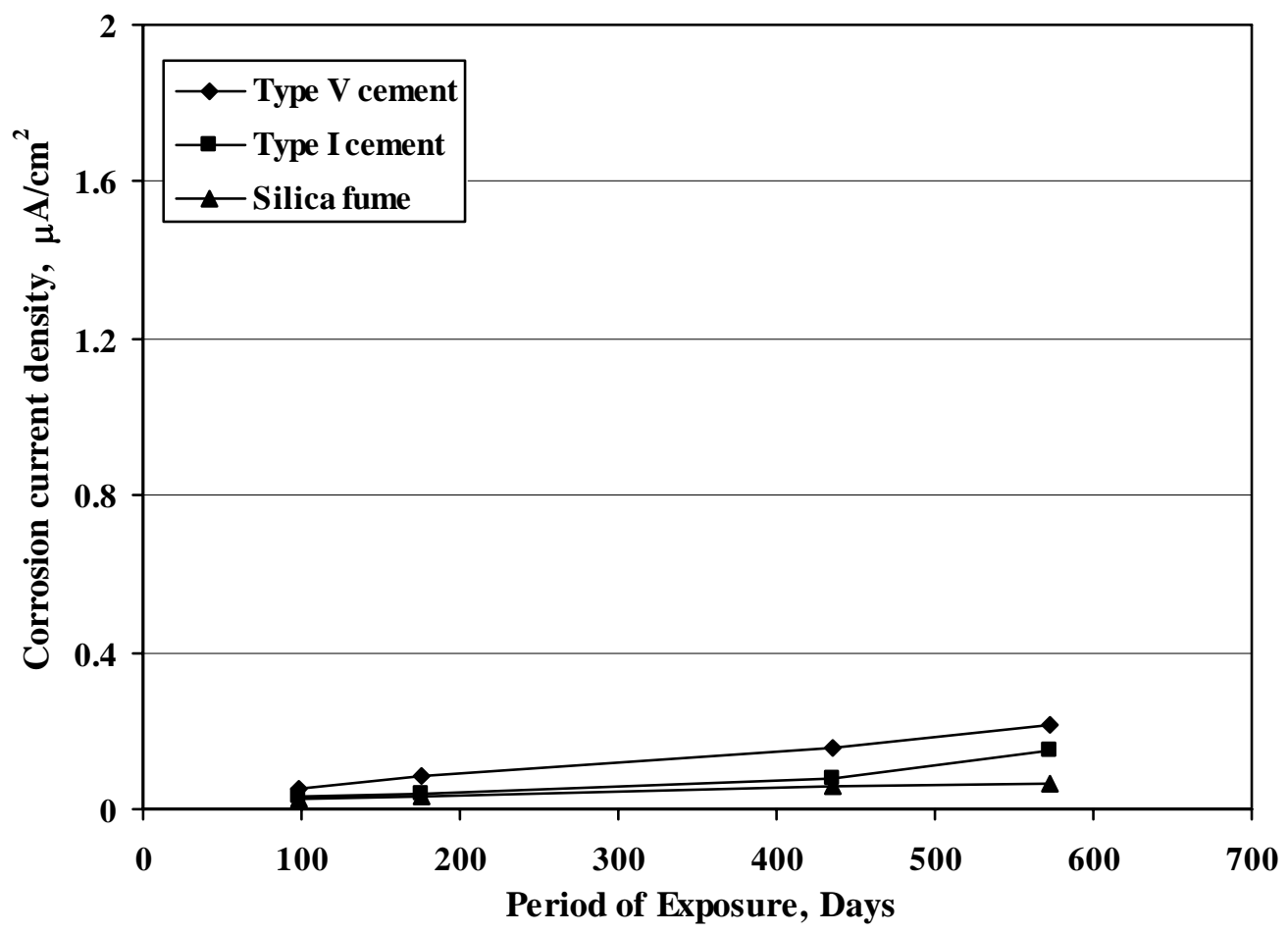

Figure 12 Corrosion current density on steel in the concrete specimens exposed to soil with a chloride concentration of $0.2 \%$.

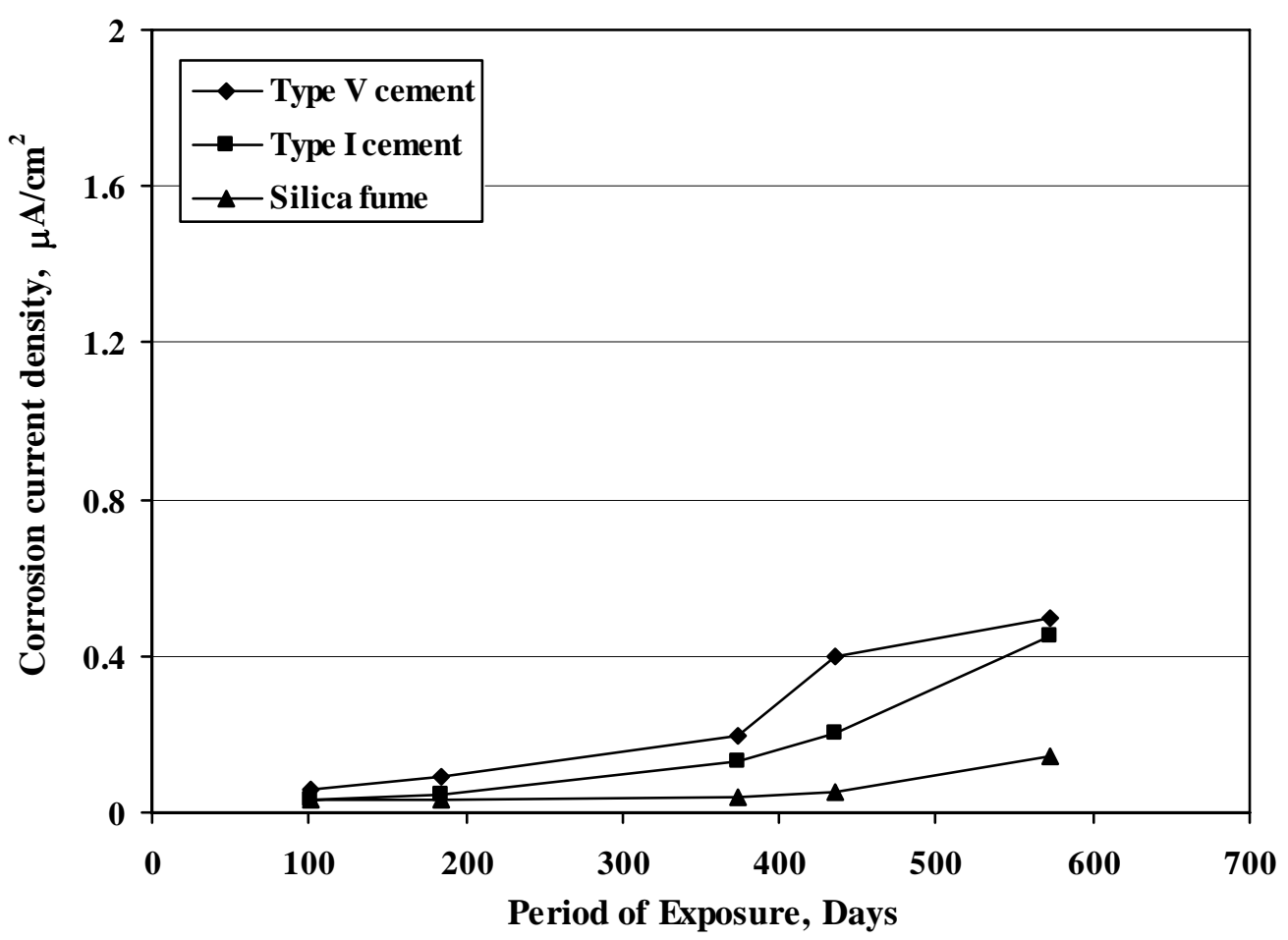

Figure 13 Corrosion current density on steel in the concrete specimens exposed to soil with a chloride concentration of $0.5 \%$. 


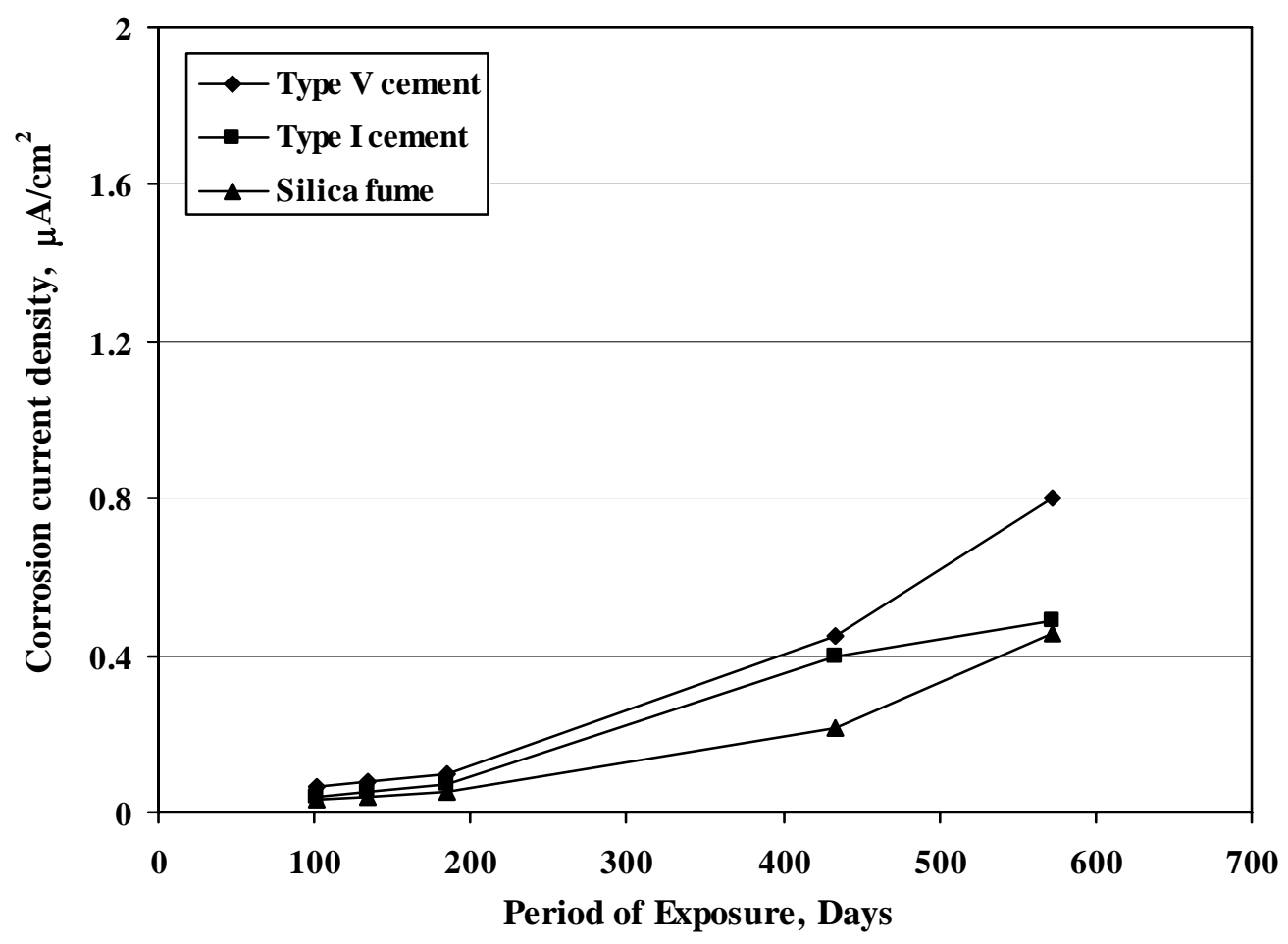

Figure 14 Corrosion current density on steel in the concrete specimens exposed to soil with a chloride concentration of $1 \%$.

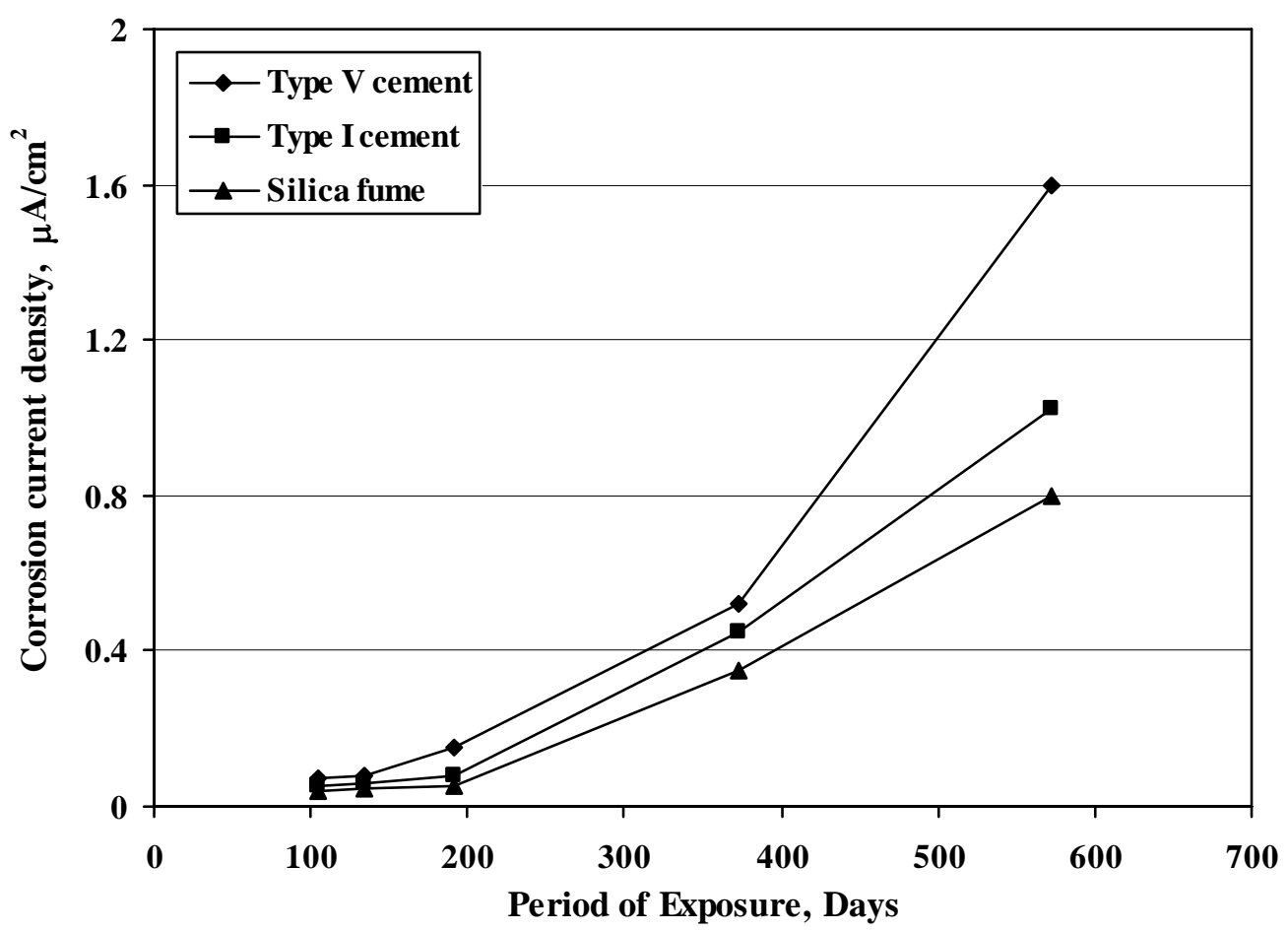

Figure 15 Corrosion current density on steel in the concrete specimens exposed to soil with a chloride concentration of $2 \%$. 


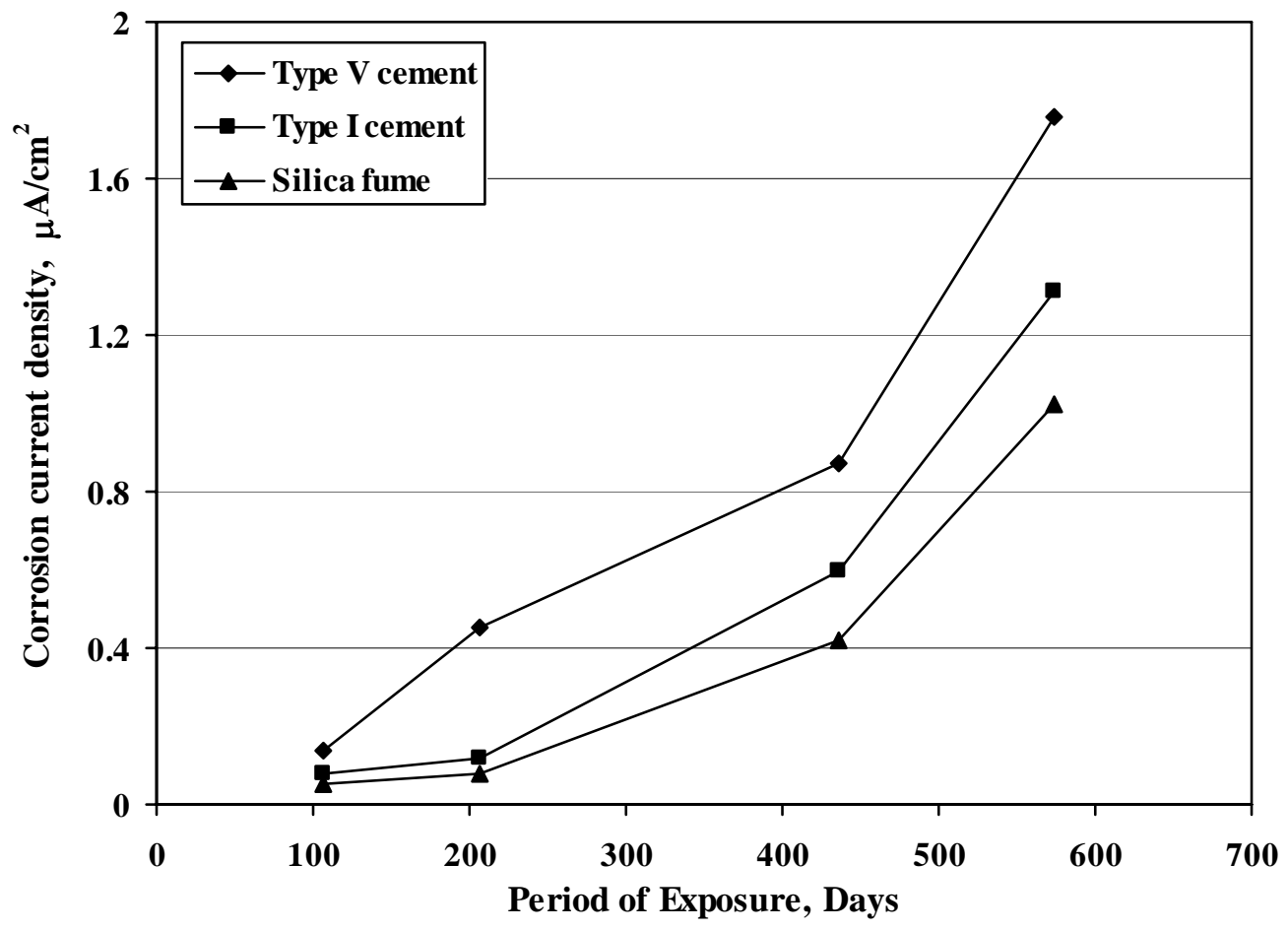

Figure 16 Corrosion current density on steel in the concrete specimens exposed to soil with a chloride concentration of $3 \%$.

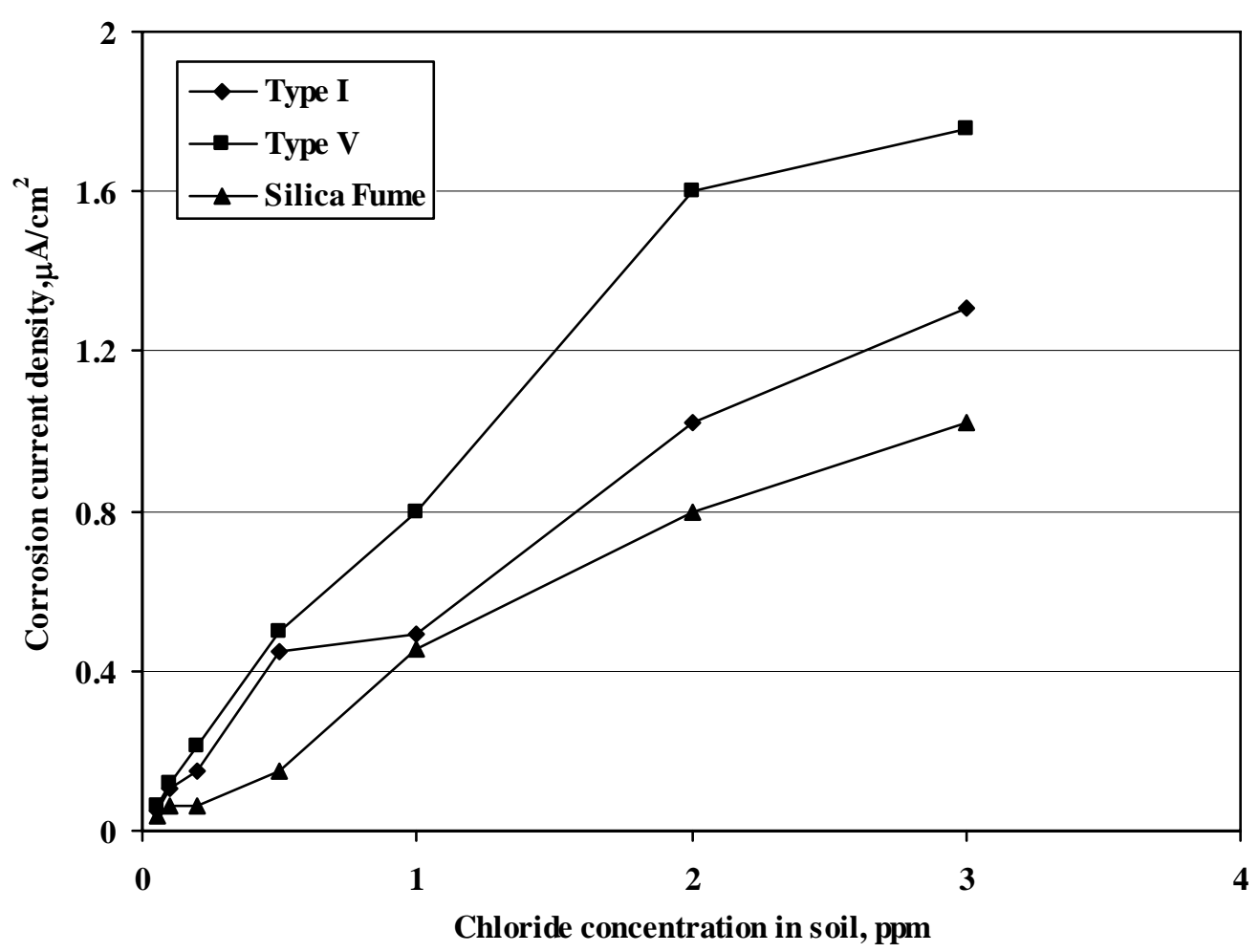

Figure 17 Corrosion current density on steel in the concrete specimens exposed to soil with varying chloride concentration. 


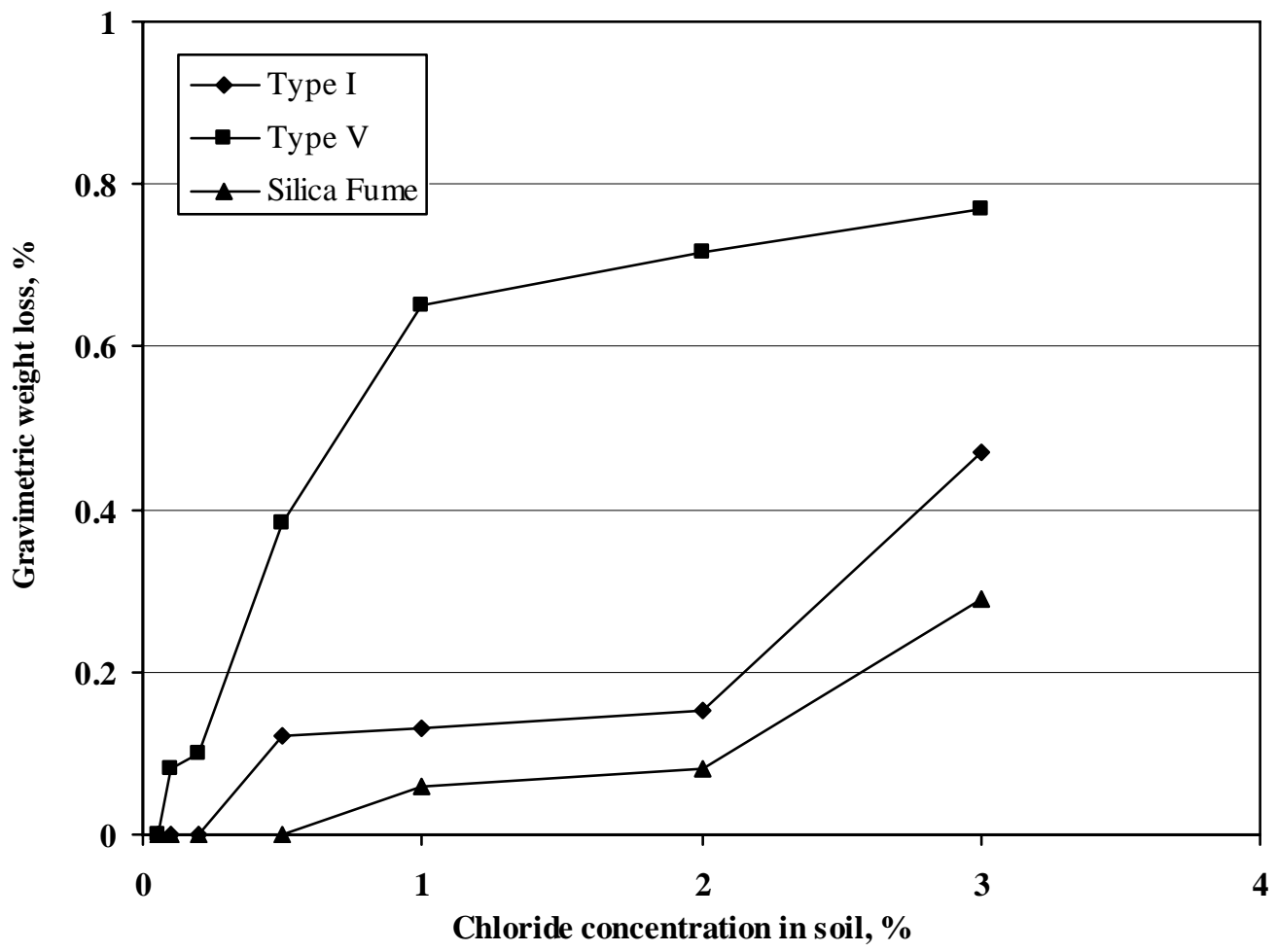

Figure 18 Gravimetric weight loss of steel in the concrete specimens exposed to soil with varying chloride concentration.

D:MMiscellaneous docs\soil paper 